\title{
Novas ocorrências de fungos conidiais para América do Sul e Neotrópico
}

\author{
SHEILA MIRANDA LEÃO-FERREIRA ${ }^{1,3}$, TASCIANO DOS SANTOS SANTA IZABEL ${ }^{1}$, \\ LUÍS FERNANDO PASCHOLATI GUSMÃO ${ }^{1}$ e MARCOS FABIO OLIVEIRA MARQUES ${ }^{2}$
}

(recebido: 8 de abril de 2009; aceito: 9 de setembro de 2009)

\begin{abstract}
ABSTRAC - (New records of conidial fungi from South America and Neotropic). During investigation of conidial fungi associated with dead plant material in Serra da Jibóia, municipality of Santa Terezinha, Bahia, some interesting species were found. Endophragmiella rigidiuscula R. F. Castañeda, Murogenella lampadiformis R. F. Castañeda \& W. B. Kendr., Mycoenterolobium platysporum var. platysporum Goos and Spegazzinia deightonii (S. Hughes) Subram. are new records from South America, and Pseudoacrodictys viridescens (B. Sutton \& Alcorn) W. A. Baker \& Morgan-Jones is a new record from Neotropic. Description, comments, geographical distribution and illustrations are presented for all species.
\end{abstract}

Key words - anamorphic fungi, diversity, leaf litter, taxonomy

RESUMO - (Novas ocorrências de fungos conidiais para América do Sul e Neotrópico). Durante investigação de fungos conidiais associados a materiais vegetais em decomposição na Serra da Jibóia, município de Santa Terezinha, Bahia, algumas espécies interessantes foram encontradas. Endophragmiella rigidiuscula R. F. Castañeda, Murogenella lampadiformis R. F. Castañeda \& W. B. Kendr., Mycoenterolobium platysporum var. platysporum Goos e Spegazzinia deightonii (S. Hughes) Subram., são novos registros para a América do Sul, e Pseudoacrodictys viridescens (B. Sutton \& Alcorn) W. A. Baker \& Morgan-Jones é um novo registro para o Neotrópico. Descrição, comentários, distribuição geográfica e ilustrações são apresentadas para as espécies.

Palavras-chave - diversidade, fungos anamórficos, serapilheira, taxonomia

\section{Introdução}

Na região semi-árida brasileira há predomínio da vegetação de Caatinga e suas diversas nuances bem como outros tipos vegetacionais, que proporcionam uma heterogeneidade e complexidade das fitofisionomias (Andrade-Lima 1981). Dentre os tipos vegetacionais existentes, resquícios de Mata Atlântica também são encontrados em fragmentos encerrados na Caatinga (Velloso et al. 2002). Associados a estes tipos vegetais encontram-se os fungos e demais organismos que participam da ciclagem de nutrientes, atuando na decomposição do folhedo em um processo complexo e de suma importância para a manutenção do equilíbrio nos ecossistemas (Christensen 1989, Dix \& Webster 1995).

Na Bahia foram realizados, recentemente, estudos de fungos conidiais associados à decomposição de substratos vegetais em diversos tipos vegetacionais e regiões: campo rupestre na Chapada Diamantina

1. Universidade Estadual de Feira de Santana, Depto. de Ciências Biológicas, Laboratório de Micologia, Av. Transnordestina, s/n, Novo Horizonte, 44036-900 Feira de Santana, BA, Brasil.

2. Universidade do Estado da Bahia, Campus VII, Depto. de Educação, Laboratório de Microbiologia, Rodovia Lomanto Júnior, BR 407 km 127, 48970-000 Senhor do Bonfim, BA, Brasil.

3._Autor para correspondência: sheila1leao@yahoo.com.br
(Barbosa \& Gusmão 2005, Gusmão \& Barbosa 2005, Cruz et al. 2007b), em fragmento de Mata Atlântica na Serra da Jibóia, Município de Santa Teresinha, (Marques et al. 2007, Gusmão et al. 2008), e em áreas de Caatinga selecionadas pelo Programa de Pesquisa em Biodiversidade - PPBio, na Serra de Santana (Senhor do Bonfim), Raso da Catarina (Paulo Afonso) e Dunas do São Francisco (Pilão Arcado) (Castañeda-Ruiz et al. 2006, Cruz et al. 2007a, 2008, Leão-Ferreira et al. 2008). Esses estudos revelaram novas ocorrências de fungos conidiais para o Brasil, América do Sul e Neotrópico, bem como novas espécies.

O presente trabalho teve como objetivo realizar a caracterização das espécies que constituem novos registros para a América do Sul e Neotrópico, associadas à decomposição de substratos vegetais em um fragmento de Mata Atlântica na Serra da Jibóia, Bahia, contribuindo para ampliação do conhecimento da distribuição geográfica das espécies encontradas.

\section{Material e métodos}

A Serra da Jibóia localiza-se no Município de Santa Terezinha, Bahia (1251' S e $39^{\circ} 28^{\prime}$ W) e constitui-se de um fragmento de Mata Atlântica encerrado na vegetação de Caatinga. Apresenta em seu topo um afloramento gnássicogranítico com cerca de 750-800 m de altitude, sobre o qual se 
desenvolve uma vegetação de campo rupestre, e nas encostas um fragmento florestal perenifólio, presente durante todo o ano, e na base a vegetação de Caatinga (Queiroz et al. 1996, Carvalho-Sobrinho \& Queiroz 2005).

Durante expedições realizadas à Serra da Jibóia no período de julho de 2004 a março de 2007, foram coletadas amostras contendo 20 substratos vegetais em decomposição de diversas espécies vegetais e armazenadas em sacos de papel tipo Kraft. No laboratório a serapilheira foi submetida à técnica de lavagem em água corrente (Castañeda-Ruiz 2005). Após secagem, as amostras foram fragmentadas e acondicionadas em câmaras-úmidas. Durante 30 dias, estruturas de reprodução dos fungos foram isoladas, sob estereomicrocópio, com auxílio de agulhas (do tipo usado para aplicação de insulina) e transferidas para meio de montagem permanente com resina PVL (Trappe \& Schenck 1982). A identificação das espécies foi realizada comparando as estruturas reprodutivas encontradas com as descrições apresentadas em bibliografia especializada. O material foi depositado no Herbário da Universidade Estadual de Feira de Santana (HUEFS).

\section{Resultados e discussão}

Endophragmiella rigidiuscula R. F. Castañeda, Fungi Cubenses III (La Habana): 9. 1988.

Figuras 1-2

Conidióforos macronemáticos, mononemáticos, simples, eretos, retos, cilíndricos, 0-1-septados, lisos, castanhos na base, castanho-claros no ápice, 37,5-65 × 3-4,5 $\mu \mathrm{m}$; células conidiogênicas monoblásticas, integradas, terminais, constrictas; conídios solitários, obovóides, lisos, secos, 3-distoseptados, castanhos, 1827,5 × 10-15 $\mu \mathrm{m}$. Secessão rexolítica.

Material examinado: BRASIL. BAHIA: Santa Terezinha, Serra da Jibóia, sobre folhas em decomposição de Andira fraxinifolia Benth., 05-IV-2005, S.M. LeãoFerreira s.n. (HUEFS 98004).

Distribuição geográfica: Cuba (Castañeda-Ruiz 1988).

O gênero foi estabelecido por B. Sutton com a espécie-tipo Endophragmiella pallescens B. Sutton (Sutton 1973). Endophragmiella rigidiuscula foi descrita, pela primeira vez, sobre folhas em decomposição de Byrsonima crassifolia (L.) D. C. Viñales (Castañeda-Ruiz 1988). Endophragmiella bisbyi (B. Sutton) S. Hughes, E. boothii (M. B. Ellis) S. Hughes, E. fuliginosa (B. Sutton) S. Hughes e E. subolivacea (Ellis \& Everh.) S. Hughes apresentam conídios obovóides, em geral 3-euseptados, diferindo de E. rigidiuscula por esta não possuir septos verdadeiros, apresentando conídios obovóides 3-distoseptados (Castañeda-Ruiz 1988, Hughes 1979).
O material examinado está de acordo com a descrição original, diferindo desta pela por apresentar conidióforos menores e constrição na célula conidiogênica. Este constitui o segundo registro da espécie e o primeiro para a América do Sul.

Murogenella lampadiformis R. F. Castañeda \& W. B. Kendr., University of Waterloo Biology Series 33:26. 1990.

Figuras 3-4

Esporodóquio presente; conidióforos reduzidos a células conidiogênicas; células conidiogênicas originadas diretamente da hifa, monoblásticas, determinadas, lisas, 5-7 × 2,5-3 $\mu \mathrm{m}$; conídios solitários, castanho-claros, clavados a obpiriformes, ápice arredondado, base estreita, 15-23 × 8-10 $\mu \mathrm{m}$ no ápice, 2-euseptados na base, 2-4-distoseptados na porção apical.

Material examinado: BRASIL. BAHIA: Santa Terezinha, Serra da Jibóia, sobre folhas em decomposição de Andira fraxinifolia Benth, 21-III-2005, S.M. LeãoFerreira s.n. (HUEFS 97978).

Distribuição geográfica: Cuba (Castañeda-Ruiz \& Kendrick 1990).

O gênero foi descrito em 1965, com a espécie-tipo Murogenella terrophila Goos \& E. F. Morris (Goos \& Morris 1965). Este gênero é caracterizado pelo conidioma em forma de esporodóquio, conídios euseptados na base e distoseptados na região apical. Murogenella lampadiformis foi descrita originalmente sobre folhas em decomposição e, segundo CastañedaRuiz \& Kendrick (1990), esta espécie difere de $M$. eucalypti B. Sutton \& Sharma e de M. terrophila pela morfologia, dimensões e septação dos conídios. Este constitui o segundo registro da espécie e o primeiro para a América do Sul.

Mycoenterolobium platysporum var. platysporum Goos, Mycologia 62(1):172. 1970.

Figuras 5-6

Conidióforos micronemáticos, inconspícuos, freqüentemente ausentes; células conidiogênicas monoblásticas, integradas, determinadas, cilíndricas a subesféricas; conídios solitários, lisos, forma variável, muriformes, castanho-escuros, fortemente aplanados e compostos de fileiras de células que partem radialmente do ponto de união do conídio com a célula conidiogênica, 52,5-70 × 60-105 $\mu \mathrm{m}$.

Material examinado: BRASIL. BAHIA: Santa Terezinha, Serra da Jibóia, sobre folhas em decomposição, 02-X-2006, T.S. Santa Izabel s.n. (HUEFS 122179). 
Distribuição geográfica: Cuba (Mercado-Sierra \& Mena-Portales 1986), Estados Unidos da América (Goos 1970), Índia (Farr et al. 2007), México (Heredia-Abarca \& Mercado-Sierra 1998).

Mycoenterolobium é monoespecífico, encontrado pela primeira vez sobre madeira de Araucaria $s p$. em decomposição no Havaí (Goos 1970). O gênero caracteriza-se pela a presença de conidióforos inconspícuos, hialinos ou subhialinos, lisos; células conidiogênicas cilíndricas, ampuliformes ou subesféricas e conídios muriformes, semicirculares a flabeliformes (Goos 1970, Ellis 1971, Chamuris et al. 1985). São conhecidas duas variedades: Mycoenterolobium platysporum var. platysporum Goos e Mycoenterolobium platysporum var. magnum Mercado \& J. Mena. Mycoenterolobium platysporum var. platysporum

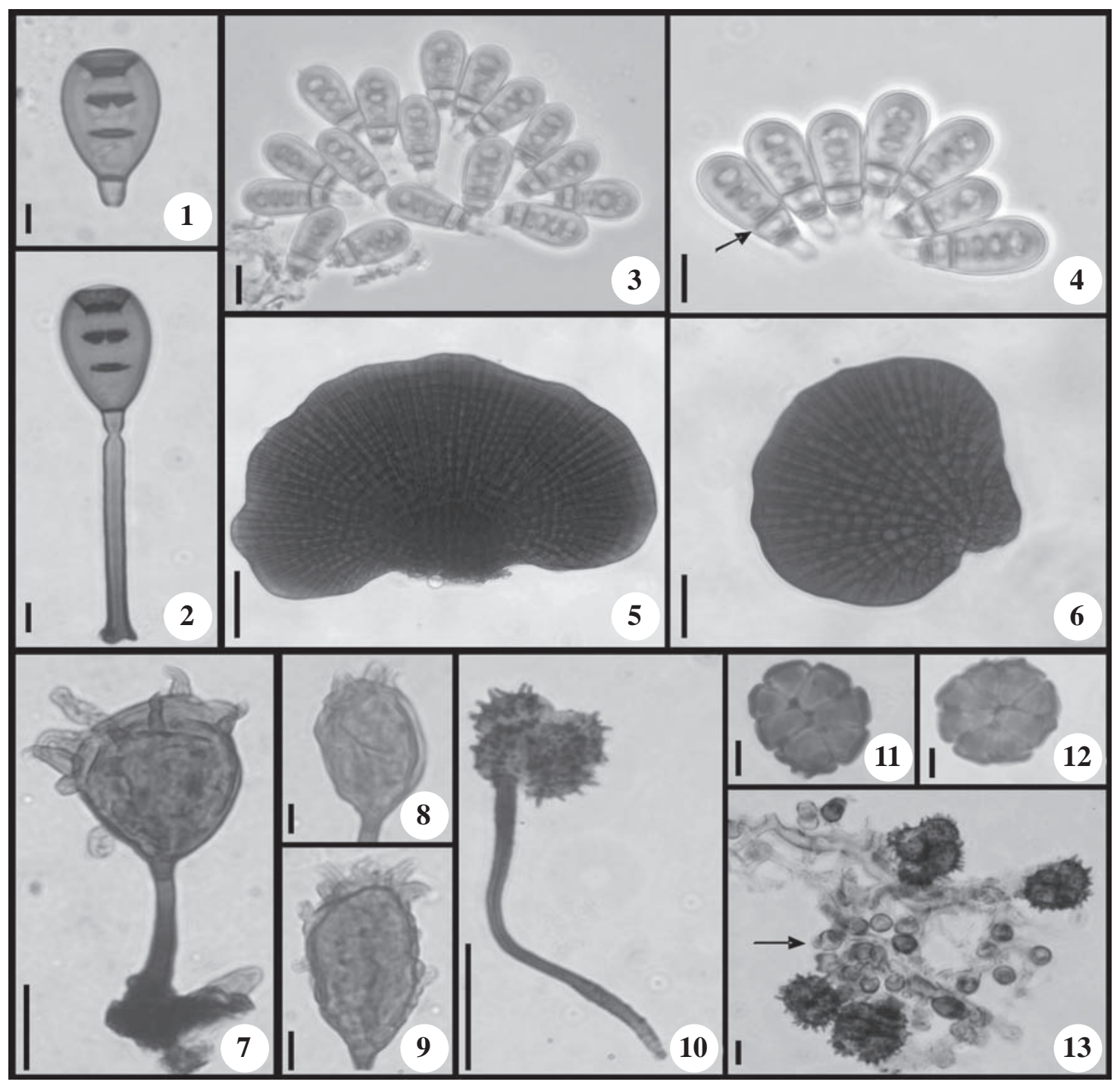

Figuras 1-13.1-2. Endophragmiella rigidiuscula. 1. Conídio. 2. Conidióforo, célula conidiogênica e conídio. 3-4. Murogenella lampadiformis. 3. Células conidiogênicas e conídios. 4. Detalhe da septação do conídio (seta). 5-6. Conídios de Mycoenterolobium platysporum. 7-9. Pseudoacrodictys viridescens. 7. Conidióforo, célula conidiogênica e conídio. 8-9. Conídios. 10-13. Spegazzinia deightonii. 10. Conidióforo, conídio tipo $a$ com espinhos curtos. 11-12. Conídios tipo $b$ muriformes. 13. Detalhe da célula mãe do conidióforo (seta). Barra $=25 \mu \mathrm{m}(7,10) ; 10 \mu \mathrm{m}(2,3,4,5,6,8,9) ; 5 \mu \mathrm{m}(1,11,12,13)$.

Figures 1-13. 1-2. Endophragmiella rigidiuscula. 1. Conidium. 2. Conidiophore, conidiogenous cell and conidium. 3-4. Murogenella lampadiformis. 3. Conidiogenous cells and conidia. 4. Detail of conidium septation (arrow). 5-6. Conidia of Mycoenterolobium platysporum. 7-9. Pseudoacrodictys viridescens. 7. Conidiophore, conidiogenous cell and conidium. 8-9. Conidia. 10-13. Spegazzinia deightonii. 10. Conidiophore, conidium $a$ with short spines. 11-12. Conidia $b$ muriform. 13. Detail of conidiophore mother cell (arrow). Bar $=25 \mu \mathrm{m}(7,10) ; 10 \mu \mathrm{m}(2,3,4,5,6,8,9) ; 5 \mu \mathrm{m}(1,11,12,13)$. 
diferencia-se de $M$. platysporum var. magnum por apresentar conídios menores e com menor variação morfológica (Mercado-Sierra \& Mena-Portales 1986). O material examinado está de acordo com as descrições de Ellis (1971) e Heredia-Abarca \& Mercado-Sierra (1998), porém, apresenta conídios menores em comprimento que os descritos por Goos (1970), Crane \& Schoknecht (1982) e Chamuris et al. (1985). Essa é a primeira ocorrência da espécie para a América do Sul.

Pseudoacrodictys viridescens (B. Sutton \& Alcorn) W. A. Baker \& Morgan-Jones, Mycotaxon 85:386. 2003. 三 Acrodictys viridescens B. Sutton \& Alcorn, Proceedings of the Royal Society of Queensland 95:45. 1984.

Figuras 7-9

Conidióforos macronemáticos, mononemáticos, simples, eretos, retos, lisos, negros na base, castanhoescuros no ápice, 26-62 × 5-7 $\mu$ m; células conidiogênicas monoblásticas, integradas, terminais, proliferação percurrente; conídios multicelulares, subglobosos a clavados, lisos, solitários, castanho-escuros, 35-48 × 19-30 $\mu \mathrm{m}$; apêndices uncinados ou curvos, castanhos, $7-11 \times 2-3 \mu \mathrm{m}$.

Material examinado: BRASIL. BAHIA: Santa Teresinha, Serra da Jibóia, sobre galhos em decomposição, 28-II-2006, M.F.O Marques s.n. (HUEFS 125451); idem, 16-VII-2006 (HUEFS 125452).

Distribuição geográfica: Austrália [como Acrodictys viridescens B. Sutton \& Alcorn (Sutton \& Alcorn 1984)].

Pseudoacrodictys foi proposto por W. A. Baker \& Morgan-Jones, para acomodar sete espécies anteriormente incluídas em Acrodictys M. B. Ellis, caracterizadas por apresentarem conídios grandes, irregulares, multicelulares, pigmentados, com septos orientados obliquamente, além da presença de apêndices (Baker \& Morgan-Jones 2003). Após este trabalho foi descrito P. dimorphospora Somrithipol \& E. B. G. Jones associado a colmo de bambu na Tailândia (Somrithipol \& Jones 2003). Dentre as espécies do gênero seis apresentam protuberâncias ou apêndices no conídio: $P$. appendiculata (M. B. Ellis) W. A. Baker \& MorganJones, P. brevicornuta (M. B. Ellis) W. A. Baker \& Morgan-Jones, P. corniculata (R. F. Castañeda) W. A. Baker \& Morgan-Jones, P. dimorphospora Somrithipol \& E. B. G. Jones, P. eickeri (Morgan-Jones) W. A. Baker \& Morgan-Jones e P. viridescens (B. Sutton \& Alcorn) W. A. Baker \& Morgan-Jones. Pseudoacrodictys viridescens pode ser diferenciado das demais espécies com apêndice pela forma uncinada ou curva dos apêndices, distalmente presentes no conídio. No material estudado, os conidióforos apresentaram-se maiores que os referidos na descrição original e os conídios menores que os reportados por Sutton \& Alcorn (1984) e Baker \& Morgan-Jones (2003). Apesar das menores dimensões dos conídios, os exemplares examinados apresentam características marcantes da espécie, como a morfologia dos conídios e apêndices uncinados nos mesmos. Este constitui o segundo registro da espécie e o primeiro para o Neotrópico.

Spegazzinia deightonii (S. Hughes) Subram, Journal of the Indian Botanical Society 35:78. 1956. 三Spegazzinia tessarthra var. deightonii S. Hughes, Mycol. Pap. 50:65. 1953.

Figuras 10-13

Conidióforos macronemáticos, mononemáticos, basáuxicos, ornamentados, retos a flexuosos, castanhoescuros, 37,5-102 × 2,5-4,5 $\mu \mathrm{m}$, ápice 1,5-3 $\mu \mathrm{m}$, originados de células-mãe cupuliformes a globosas, simples, 5-8 × 4-6 $\mu \mathrm{m}$; células conidiogênicas monoblásticas, cilíndricas, integradas, terminais; conídios solitários, castanho-escuros, multicelulares, de dois tipos: conídios tipo a subglobosos, 8-células cada, células 7,5-10 $\mu \mathrm{m}$ de diâm., espinhos com 1,5-3 $\mu \mathrm{m}$ de compr.; conídios tipo $b$ com 8 células, co-planados, 9-18 $\times$ 7,5-15 $\mu \mathrm{m}$. Secessão rexolítica.

Material examinado: BRASIL. BAHIA: Santa Teresinha, Serra da Jibóia, sobre folhas em decomposição de Vellozia variegata Goeth. \& Hens., 31-I-2005, S.M. Leão-Ferreira s.n. (HUEFS 97979).

Distribuição geográfica: Cuba (Mercado-Sierra 1984), Gana, Índia, Nigéria, Nova Guiné, Porto Rico, Serra Leoa (Ellis 1971), Hong Kong (Wong \& Hyde 2001), Ilhas Cook, Ilhas Salomão, Ilhas Vanuatu, Malásia (Mckenzie 2007), Japão (Matsushima 1993), México (Heredia et al. 1995) e Taiwan (Matsushima 1980).

Spegazzinia foi descrito por Saccardo, em 1879, com a espécie-tipo $S$. ornata Sacc. O gênero caracteriza-se por apresentar conidióforos basáuxicos, células conidiogênicas integradas e em geral com dois tipos morfologicamente distintos de conídios (Chen \& Tzean 2000). Spegazzinia deightonii foi descrita associada à diversas plantas, incluindo Andropogon sp., Axonopus sp., Borassus sp., Dioscorea sp. e Oryza sp. (Ellis 1971). A espécie encontrada difere das demais espécies do gênero, que também produzem dois tipos morfológicos de conídios ( $a$ e $b$ ), como S. tessarthra (Berk. \& M. A. Curtis) Sacc. e S. lobulata (Berk. \& Broome) Höhn., por apresentar oito células nos conídios tipo $a$ e $b$, enquanto 
as espécies citadas apresentam apenas quatro células. O material examinado apresenta conídios menores quando comparados aos reportados por Ellis (1971) e Heredia et al. (1995). Este constitui o primeiro registro da espécie para a América do Sul.

Agradecimentos - Os dois primeiros autores agradecem à Probic/UEFS e à Fapesb, respectivamente, pelas bolsas de iniciação científica concedidas. Luis Fernando P. Gusmão agradece ao CNPq (471619/04-3) pelo apoio financeiro.

\section{Referências bibliográficas}

ANDRADE-LIMA, D. 1981. The Caatinga dominium. Revista Brasileira de Botânica 4:149-153.

BAKER, W.A. \& MORGAN-JONES, G. 2003. Notes on Hyphomycetes. XCI. Pseudoacrodictys, a novel genus for seven taxa formerly placed in Acrodictys. Mycotaxon 85:371-391.

BARBOSA, F.F. \& GUSMÃO, L.F.P. 2005. Two Speiropsis species (Anamorphic Fungi-Hyphomycetes) from Bahia State, Brasil. Acta Botanica Brasilica 19:515-518.

CARVALHO-SOBRINHO, J.G. \& QUEIROZ, L.P. 2005. Composição florística de um fragmento de Mata Atlântica na Serra da Jibóia, Santa Terezinha, Bahia, Brasil. Sitientibus-Série Ciências Biológicas 5:20-28.

CASTAÑEDA-RUIZ, R.F. 1988. Fungi Cubenses III. Instituto de Investigaciones Fundamentales en Agricultura Tropical "Alejandro de Humboldt”, La Habana.

CASTAÑEDA-RUIZ, R.F. 2005. Metodología en el estudio de los hongos anamorfos. In Anais do V Congresso Latino Americano de Micologia, Brasília, p.182-183.

CASTAÑEDA-RUIZ, R.F. \& KENDRICK, B. 1990. Conidial Fungi from Cuba: II. University of Waterloo Biology Series 33:1-53.

CASTAÑEDA-RUIZ, R.F., GUSMÃO, L.F.P., HEREDIAABARCA, G. \& SAIKAWA, M. 2006. Some hyphomycetes from Brazil. Two new species of Brachydesmiella, two new combinations for Repetophragma and new records. Mycotaxon 95:261270.

CHAMURIS, G.P., FALK, S.P. \& WANG, C.J.K. 1985. Denticularia limoniformis, Lemkea sphaerospora and Mycoenterolobium platysporum (Hyphomycetes): new records for North America. Mycotaxon 24:319-324.

CHEN, J.L. \& TZEAN, S.S. 2000. Three species of Spegazzinia (hyphomycetes) from Taiwan. Fungal Science 15:81-87.

CHRISTENSEN, M. 1989. A view of fungal ecology. Mycologia 81:1-19.

CRANE, J.L. \& SCHOKNECHT, J.D. 1982. Hyphomycetes from freshwater swamps and hammocks. Canadian Journal of Botany 60:369-378.
CRUZ, A.C.R., GUSMÃO, L.F.P., LEÃO-FERREIRA, S.M. \& CASTAÑEDA- RUIZ, R.F. 2007a. Conidial fungi from the semi-arid Caatinga biome of Brazil. Diplococcium verruculosum sp. nov. and Lobatopedis longistriatum sp. nov. Mycotaxon 102:33-38.

CRUZ, A.C.R., MARQUES, M.F.O. \& GUSMÃO, L.F.P. 2007b. Fungos anamórficos (Hyphomycetes) da Chapada Diamantina: novos registros para o Estado da Bahia e Brasil. Acta Botanica Brasilica 21:847-855.

CRUZ, A.C.R., LEÃO-FERREIRA, S.M., BARBOSA, F.R. \& GUSMÃO, L.F.P. 2008. Conidial fungi from semiarid Caatinga biome of Brazil. New and interesting Dictyochaeta species. Mycotaxon 106:15-27.

DIX, N.J. \& WEBSTER, J. 1995. Fungal ecology. University Press, Cambridge.

ELLIS, M.B. 1971. Dematiaceous Hyphomycetes. Commonwealth Mycological Institute, Kew.

FARR, D.F., ROSSMAN, A.Y., PALM, M.E. \& MCCRAY, E.B. 2007. Fungal Databases, Systematic Botany \& Mycology Laboratory, ARS, USDA. http://nt.ars-grin. gov/fungaldatabases/ (acesso em 12/04/2007).

GOOS, R.D. 1970. A new genus of Hyphomycetes from Hawaii. Mycologia 62:171-175.

GOOS, R.D. \& MORRIS, E.F. 1965. Murogenella terrophila - a new dematiaceous fungus from soil. Mycologia 57:776-781.

GUSMÃO, L.F.P. \& BARBOSA, F.R. 2005. Hemibeltrania (anamorphic fungi - Hyphomycetes) from Bahia State, Brazil. Sitientibus-Série Ciências Biológicas 5:17-19.

GUSMÃO, L.F.P., LEÃO-FERREIRA, S.M., MARQUES, M.F.O. \& ALMEIDA, D.A.C. 2008. New species and records of Paliphora from the Brazilian semi-arid region. Mycologia 100:306-309.

HEREDIA, G., MERCADO-SIERRA, A. \& MENAPORTALES, J. 1995. Conidial fungi from leaf litter in mesophilic cloud forest of Veracruz, México. Mycotaxon 55:473-490.

HEREDIA-ABARCA, G. \& MERCADO-SIERRA, A. 1998. Tropical hyphomycetes of Mexico. III. Some species from the Calakmul Biosphere Reserve Campeche. Mycotaxon 68:137-143.

HUGHES, S.J. 1979. Relocation of species of Endophragmia auct. with notes on relevant generic names. New Zealand Journal of Botany 17:139-188.

LEÃO-FERREIRA, S.M., CRUZ, A.C.R., CASTAÑEDA RUIZ, R.F. \& GUSMÃO, L.F.P. 2008. Conidial fungi from the semi-arid Caatinga biome of Brazil. Brachysporiellina fecunda sp. nov. and some new records for Neotropica. Mycotaxon 104:309-312.

MARQUES, M.F.O., BARBOSA, F.R., GUSMÃO, L.F.P., CASTAÑEDA RUIZ, R.F. \& MAIA, L.C. 2007. Conidial fungi from the semi-arid Caatinga biome of Brazil. Cubasina microspora sp. nov., a note on $C$. albofusca, and some new records for South America. Mycotaxon 102:17-23. 
MATSUSHIMA, T. 1980. Saprophytic Microfungi from Taiwan. Part 1: Hyphomycetes. Matsushima Mycological Memoirs n.1. Matsushima Fungus Collection, Kobe.

MATSUSHIMA, T. 1993. Matsushima Mycological Memoirs n.7. Matsushima Fungus Collection, Kobe.

MCKENZIE, E. 2007. Nzfungidatabase. Disponível em http://nzfungi.landcareresearch.co. nz/html/ mycology. asp (acesso em 05/05/2007).

MERCADO-SIERRA, A. 1984. Hifomicetes Demaciaceos de Sierra del Rosario, Cuba. Editorial Academica, Havana.

MERCADO-SIERRA, A. \& MENA-PORTALES, J. 1986. Hifomicetes de Topes de Collantes, Cuba I. Especies holoblasticas. Acta Botanica Hungarica 32:189-205.

QUEIROZ, L.P., SENA, T.S.N. \& COSTA, M.J.S.L. 1996. Flora vascular da Serra da Jibóia, Santa Terezinha Bahia. I: o campo rupestre. Sitientibus-Série Ciências Biológicas 15:27-40.

SOMRITHIPOL, S. \& JONES, E.B.G. 2003. Pseudoacrodictys dimorphospora sp. nov., a new graminicolous hyphomycete from Thailand. Sydowia 55:365-371.
SUTTON, B.C. 1973. Hyphomycetes from Manitoba and Saskatchewan, Canada. Mycological Papers 132: 1-143.

SUTTON, B.C. \& ALCORN, J.L. 1984. Microfungi from Queensland II. Pseudopetrakia and similar taxa. Proceedings of the Royal Society of Queensland 95: 41-46.

TRAPPE, J.M. \& SCHENCK, N.C. 1982. Taxonomy of fungi forming endomycorrhizae. In Methods and principles of mycorrizal research (N.C. Schenck ed.). The American Phytopathological Society. St. Paul, p.1-9.

VELLOSO, A.L., SAMPAIO, E.V.S.B. \& PAREYN, F.C.C. (eds.). 2002. Ecorregiões propostas para o Bioma Caatinga. Associação de Plantas do Nordeste, Instituto de Conservação Ambiental, The Nature Conservancy do Brasil. Recife.

WONG, M.K.M. \& HYDE, K.D. 2001. Diversity of fungi on six species of Gramineae and one species of Cyperaceae in Hong Kong. Mycological Research 150:1485-1491. 